INTERNATIONAL DESIGN CONFERENCE - DESIGN 2018

https://doi.org/10.21278/idc.2018.0484

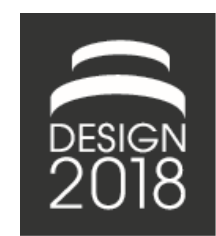

\title{
HOW TO FOSTER INNOVATION? FINDINGS AND HYPOTHESES FOR COLLABORATIONS BETWEEN RESEARCH AND INDUSTRY
}

\author{
T. Şahin, A. Cudok, S. Rapp, D. Inkermann, A. Albers, F. Wattenberg, N. Bursac and T. \\ Vietor
}

\begin{abstract}
This paper stresses the importance of collaborations to foster innovation and highlights the need for a shared understanding of innovation. To support successful collaboration we outline essential success factors and formulate hypotheses to improve collaborations focussing on SMEs. A model is introduced, allowing the identification of fields and measures to foster innovation. In addition, the concept of Product Generation Engineering is proposed to analyse past and plan future innovation activities. The discussion and hypotheses are addressed to researchers in the field of product engineering.
\end{abstract}

Keywords: open innovation, collaboration, small and medium size enterprise (SME), design practice

\section{Introduction}

The term 'innovation' is widely used but diffuse in its meaning and understanding. Existing definitions address different foci including products or processes and highlight varying means and stages of the innovation process. However, there is a great amount of literature, emphasizing the importance of collaboration to identify fields for innovations and transfer knowledge to bring up innovation, in general (West et al., 2006) and in product engineering in particular (Blessing and Seering, 2016; Riitahuhta and Oja, 2016). The required knowledge refers to both methods to plan, conduct and route the innovation process as well as knowledge about technologies, focussing on manufacturing technologies as well as IT-tools, for instance to provide and handle information within enterprises. Practice in research and industry shows that the diffuse understanding of innovation often hinders to initiate goal-oriented and successful collaborations. The authors therefore argue that it is essential to develop consistent concepts to describe and identify fields of innovation as well as concepts to support the understanding of past and future innovation processes. These elements should be part of research work to support the transfer of research results to practice and increase application of existing and new methods in industry (Wallace, 2011). At the same time, these activities will lead to new insights for research, since the use of methods in practice will highlight their usability and gaps for future research. Based on this motivation in this contribution, we discuss lessons learned from past collaborations between research and industry in the field of product engineering.

Major object of this contribution is to discuss findings of successful and ineffective collaborations between research and industry. The discussion and hypotheses we derive are directed to researchers in the field of product engineering in order to reflect past and activate new concepts to plan and conduct collaborations and, therefore, the transfer of research results to industry. To set the focus of our research and highlight the need of orientation, in the following section, different understandings and fields of 
innovation are described. Furthermore, Product Generation Engineering is introduced as a holistic approach to understand past and plan further innovations with focus on products. In Section 3, existing approaches to foster innovation by collaborations, as well as expectations from industry and success factors are introduced based on a literature review and interviews within small and medium-sized enterprises. Based on the findings we formulate basic hypotheses to improve innovation by collaborations. In Section 4 we introduce a model and a procedure to support identification and definition of fields for innovation for goal-oriented initiation of collaborations. In Section 5, two case studies of successful collaborations are described, focussing on Product Generation Engineering (PGE) and the application of the proposed model to identify fields of innovation and collaboration. The contribution concludes with a discussion of the findings and hypotheses and an outlook for future research.

\section{Approaches to understand and classify innovation}

Innovations are considered as main drivers for the success of enterprises due to the common understanding that they gain economic benefits. According to Schumpeter (1939) this understanding can be assigned to both product and process innovations. Product innovations are based on improvements and alternations of technical products, leading to new, changed or improved properties. Process innovations are based on alternations of processes and, from a technical view, are often a result of new manufacturing processes and technologies. However, the understanding and classification of innovations mainly depends on the perspective of the domains, involved in the innovation process. Motivated by this fact in the following paragraph perspectives of different disciplines are discussed and categories to classify innovations are introduced. In addition the concept of Product Generation Engineering is introduced as an approach to analyse and plan product innovations.

\subsection{Perspectives of different disciplines}

The diffuse understanding of the term innovation in scientific and industrial context necessitate the need to clarify its basic nature with respect to different disciplines. All approaches to define the term innovation are based on the latin word 'innovare'. This brings out the novelty as the essential characteristic of an innovation. The term innovation can be further characterized by various dimensions established in the literature (Baregheh et al., 2009; Hauschildt and Salomo, 2011; Gerpott, 2013). A common distinction is made between result- and process-oriented dimensions. The result-oriented dimensions are the nature of an innovation which refers to the form of innovation as in something new, improved or changed, the type of innovation referring to the kind of innovation, the degree of innovation considering the novelty of an innovation and the aim of an innovation describing the overall result the organization wants to achieve by innovation. The process oriented dimensions contain the stages of an innovation describing all steps during an innovation process, the means of an innovation understood as a source to support the innovation process and the social context referring to the social entity, system or group of people involved in innovation processes or environmental factors affecting it. Based on this dimensions the different understandings within disciplines are outlined in Baregheh et al. (2009) analysing a representative pool of innovation definitions, including definitions in the disciplines of economics, innovation and entrepreneurship, business and management, technology, science and engineering, and organisation studies. These results highlight that aside from different foci and perspectives for innovation also different terms are used for the same intentions.

The various foci of the discipline specific perspectives also result in different approaches, methods and tools to foster innovation. Established methods are provided in a great amount of literature in the field of product engineering, see (e.g. Eversheim, 2003; Lindemann, 2009; Osterwalder et al., 2014) also referred as innovation management techniques (e.g. Hidalgo and Albors, 2008). Methods and tools to support the innovation process do usually not act in a deterministic and unique manner. The different characteristics of firms and their circumstances lead to the fact that there is no unique ideal model to foster innovation, although there are some principles of good practice (Hidalgo and Albors, 2008). Furthermore, the knowledge about methods in industry in general is limited. Thus, it becomes a task for researchers in product development to transfer methodical knowledge into industry (Wallace, 2011). The variance of definitions of 'innovation' as well as applied innovation management techniques 
illustrates the different understandings of partners within collaborations. For this reason, it is essential to develop a common understanding of the specific intentions as a basis for collaborations.

\subsection{Common approaches to classify innovation}

In order to support the classification and, thus, the planning of innovation processes, different approaches are described in literature. Most classifications define the kind of innovation from a retrospective view. For instance, Henderson and Clark (1990) distinguish four categories of innovations based on the system theory, c.f. (Ropohl, 2009). Incremental innovations are characterised by small changes of single components while architectural innovations are based on changed or new arrangements of existing components from a structural view. Modular innovations are defined by a replacement of single components while sticking to the structure of the existing system. Substantial changes of both the system structure and components are referred as disruptive innovations. Here, components are replaced and the system structure is modified in order to provide new functionalities and improved properties of the product. This classification implies insights for the technical and economic risk of the innovation process, since it takes into account the knowledge (existing product, manufacturing technologies, etc.) the innovation is based on. Thus, a disruptive innovation accompanies the highest risk, while technical and economic risk of an incremental innovation is limited due to the finite changes of single components. However, the retrospective character of the classification does not allow to analyse whether a successful innovation is based on its technical or economic realization. Albers et al. (2016a) therefore proposed a categorization based on the distinction between business to business and business to customer projects for customer relation projects. As a second dimension, the implemented core technology is categorized according to its readiness differing between research, market, industry and the enterprise. Based on this categorization and the analysis of product profiles in industry, key criteria like technical feasibility, technical degree of novelty or future robustness are derived. These criteria help to characterize innovations with regard to both, its technical and economic characteristics.

Both classifications discussed the influence of existing knowledge about the product as well as for instance manufacturing technologies on the risk of the innovation process and, thus, the need to involve partners with suitable expertise.

\subsection{PGE - Product Generation Engineering}

In nearly every case new products are a purposeful combination of subsystems which are carried over from existing products and subsystems that are newly developed. Albers et al. (2015) describes this with the Product Generation Engineering approach. This approach provides a fundamental understanding of innovations in the field of product development by introducing principles how products are modified and their development processes are executed in practice. According to this existing products which serve as a reference in the development of a new product generation are called reference products. Often is a preceding product generation an important reference product, for instance in automotive industry. Possible reference products can also be competitor's products, products from other branches or a company's concepts and prototypes, which had never made it to serial production. A basic distinction can be made between internal reference products of a company, developed within the company itself, and external reference products (Albers et al., 2016a). Based on reference products, the subsystems of a new product are developed by three types of variation according to the PGE approach: carry over variation is the transfer of subsystems with adjustments only, if necessary, at the system interfaces. Embodiment variation and principle variation are new development activities with variation of the embodiment or the principle with subsequently designing a new embodiment. The PGE approach is also capable of describing the development of different variants for an existing product or the transition between different product states - called development generations - within the development process (Albers et al., 2016b; Peglow et al., 2017).

The different perspectives and classification approaches introduced in this section, highlight the importance to gain a common understanding of the field and aim of innovation when starting collaboration between industry and research. Furthermore, it becomes clear that the existing knowledge within an enterprise is a main driver but also limitation for future innovations, since it essentially 
determines the risk of the innovation process. In order to support the initiation of collaborations and foster their success in the following sections approaches to strengthen innovation capability by means of collaboration (Section 3) and a model to identify fields for innovation and collaborations (Section 4) are introduced.

\section{Approaches to strengthen innovation capability by collaboration}

Collaborations between two or more partners often lead to new concepts of products and services, reaching further than developments of only one developer (West et al., 2006). Thus, collaborations can be seen as an essential catalyst for innovation. In this section, a closer look at collaborations and their success factors is given. Open Innovation as a general concept and collective term for several types of collaboration is presented and different forms of cooperation, their initiation and criteria of success are reviewed. Here, the focus is on the collaboration of small and medium-sized enterprises (SME) with research partners and other SMEs.

\subsection{Collaboration of SMEs}

The term 'collaboration' includes a wide range of co-operations of two or more partners, for example in the development of products, processes, and a company's or institution's organization. It extends from a) including a subcontractor/supplier in the supply chain via b) integrating external knowledge into the company's innovation processes up to c) projects with equal (development) partners. Open Innovation describes the process of a company opening up their process of innovation and can be realised in different ways: A company opens up to the inside and combine its knowledge with external knowledge by licensing in or acquisition. It can also open up to the outside and support the innovation process of other companies by providing their knowledge to others. The combination of both internal and external ideas and knowledge leads to an integrated approach to innovating product-service-systems and business models and, thus, value creation (West et al., 2006). Based on this understanding, within this paper, collaborations are defined as the cooperation of at least two partners working together in a project and aiming for common objectives. Knowledge and manpower of all partners (technological and/or methodological) complement up to the necessary resources for the project that could not (or at least not in the same time frame) be processed by only one partner.

In order to ease orientation for the following sections, we introduce an idealized process of collaborative innovation processes. The process defines basic phases and highlights the impact of success factors discussed in the following paragraphs. The phases represented are derived from literature (Link, 2001; Müller, 2003; Gürtler, 2016) and include: initiation of collaboration, partner selection, planning of collaboration, implementation, and completion. Each phase is characterized by specific activities or management tasks shown in Figure 1.

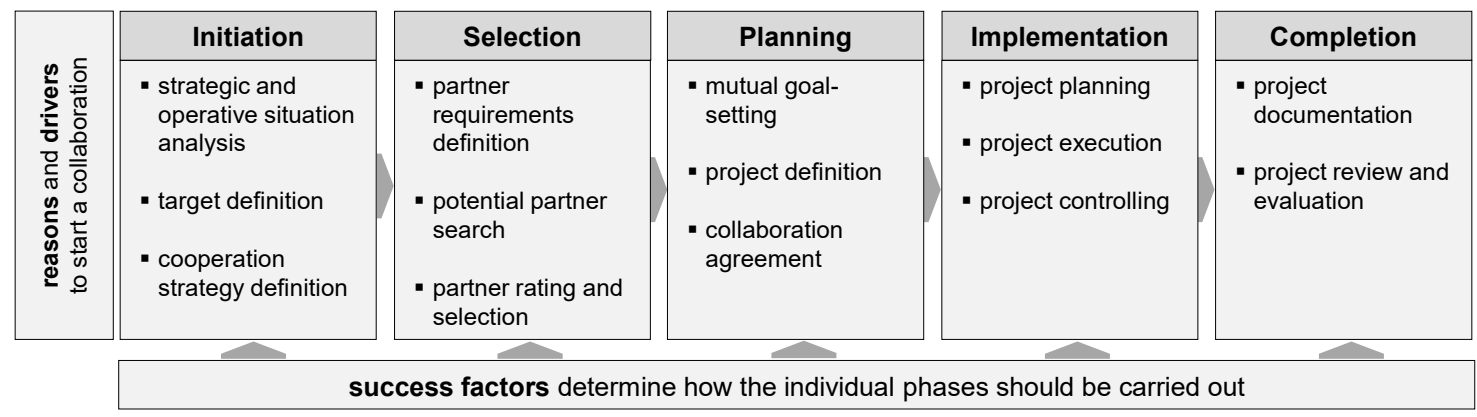

Figure 1. Phases of a collaborative innovation process

In addition, there are different reasons and drivers to start a collaboration process and various success factors influencing the process. It has to be mentioned that the collaboration process in industrial practice proceeds rarely sequential but begins and ends at different stages of an innovation process and also includes repetition of single phases. 
In the further paragraphs, a closer look is taken at what types of collaboration within industry and research exist, how collaborations are initiated, and what criteria can be used to evaluate their success. Therefore, a survey with a small number of SME has been conducted. These companies are members of the innovation network 'Synfonie' which was implemented within a project on knowledge transfer between industry and research. Five mechanical engineering companies have been chosen and a range of different positions - from project team members via design managers up to managing directors have been interviewed. Questions concerning the aspects a) types, b) initiation and c) success have been created and projected to both past and future collaborations within a list of questions for semi-structured interviews. This way, experiences and expectations of the enterprises were queried. The given statements were documented by shorthand notes. Bigliardi and Galati (2016) have been conducting a similar survey with SMEs from Italy, investigating when, how and why Open Innovation practices take place.

\subsubsection{Types of collaborations}

The definition of collaboration introduced before aligns with all of the companies' statements and understandings. All collaborations reported include at least two partners and aim at sharing knowledge or manpower in order to achieve a common object like a product, a process and/or a business model. Since various drivers may lead to collaborations (see 3.2.2) and different kinds of knowledge are exchanged, not only a collaboration between two industry partners can be counted as one of the possible constellations within Open Innovation. Combinations of industry and research partners like e.g. university institutes were also mentioned as established constellations. These findings correspond to other detailed analyses of Open Innovation practices like Bigliardi and Galati (2016). They also gathered inbound, outbound and coupled approaches and gave them overarching definitions.

\subsubsection{Initiation of collaborations}

Concerning the initiation of collaboration, two categories are of interest. First of all, drivers are relevant and, secondly, requirements for starting a collaboration were mentioned within the interviews. Several drivers may lead to collaborative projects between one or more parties: Global trends like diminishing technology cycles and, subsequently, innovation cycles have to be adapted by SMEs. This leads to difficulties within the development process. Not only is the speed of development activities a challenge, but also the increasing complexity of products leads to a lack of knowledge within SME. For example, the digitalization of a product or the reformation of business models and inclusion of services require the extension of internal knowledge. It results from the survey, that these are the most important reasons for an SME to start a collaboration. Apart from technological knowledge, it could also be methodical expertise that an SME lacks. Systematic approaches for either content-related or organizational issues can be brought to a company, mostly by research partners or consultancy. Examples mentioned are development methods, such as for modular design, or the analysis of potentials for new businesses and markets. Another driver are missing resources, e.g. time constraints and not manageable additional personnel costs. Furthermore, one reason for collaboration, especially for SMEs, is risk minimization in the fields of research or development processes by sharing the risks (West et al., 2006).

Prerequisite for the initiation is a positive and an open-minded attitude towards the collaboration with partners from industry or research. A certain basic trust concerning sharing information, new insights and findings, is the basis for a successful collaboration. Within the initiation phase of a new collaboration, it is often a critical and time consuming obstacle to earn each other's trust.

Another important factor concerning the initiation of collaborations is the search for the appropriate partners. Within the survey, it was mentioned that a partner is chosen depending on the topic and problem. In case of a more diffuse and open task, SMEs would rather contact partners from research. High quality of the work, as well as a less critical attitude concerning knowledge sharing and loss compared to industry partners, are expectations for this format of collaboration. In cases of specific problems with clearly definable system and knowledge boundaries, SMEs rather search for an industry partner with the fitting knowledge. It was mentioned that the search for partners is often difficult in the case that the company cannot refer to a suitable network of potential partners. 


\subsubsection{Success and failure of collaborations}

Various factors are influencing the success of a collaboration. Within the surveyed partners, it is not even clear whether the success of a collaboration, e.g. a development project, can be measured by finishing the project or, more subsequently, by the success of the developed system itself. Overall, it is often mentioned that a collaboration is successful when all participants have reached (at least part of) their pre-defined goals. Also, knowledge generation, leading to further projects, is mentioned as a success criterion.

On the contrary, statements concerning criteria for failure of collaborations are clearer to be defined, since they can be derived from critical experiences. These can be found both within the initiation and the execution phase of collaborations and have differing impacts on the collaboration. Content-related as well as organizational and interpersonal effects interact and affect joint projects. These are vague project tasks or imprecisely defined responsibilities in the beginning as well as promised but notexecutable competencies, leading to confusion for the project team members. Closely connected are changes of goals during the project, also leading to ambiguous subtasks and accountabilities. In the worst case, a collaboration can be cancelled for instance because of an unforeseen change of a company's strategy (especially when it comes to collaborations with larger companies). Furthermore, missing trust and openness to new ideas and their exchange as well as the dominant behaviour of one partner complicate the relation. Often, these conditions are aggravated by a lack of communication between the collaborating partners. Moreover, misjudgements concerning the required time for a project and decreasing motivation affect the success of a project. Furthermore, missing financial resources could be a reason for an SME not to start a collaboration in the first place.

Drivers, requirements, success criteria and possible obstacles are strongly interrelated and mutually dependant. Another possibility to categorize them is given by Bigliardi and Galati (2016), formulating economic and financial issues, collaboration or internal factors as well as knowledge issues. All of the factors found in our survey could also be classified by these categories.

\subsection{Hypotheses to improve collaborations}

Derived from the statements and arguments for or against collaboration, hypotheses are derived to ease and improve collaborations. As before, the needs for action could be divided into the categories of initiation and implementation but, mostly, the hypotheses that need to be addressed during initiation have to be kept up during the whole collaboration.

From a research point of view, many SMEs need systematic support when searching for the right topic, tasks, partner and setting for a collaborative project. Addressing the problem of missing basic trust towards sharing and exchanging ideas with external partners, the right boundary conditions have to be set. The search for the right partner is supported, as competencies can easily be matched within the network. Furthermore, the connection can be complemented by clarifying the environment for collaborations. Concerning the implementation of collaborations, a neutral and professional project management can support a positive and thriving project progression. Kick-Off meetings as well as team events within the project help to support and keep the interpersonal relations of team members and their motivation up. Regarding content-related and organizational issues, the support of defining and managing the project tasks, responsibilities and the type of cooperation is of essential importance in the early phases of collaboration, in particular for inexperienced partners. Especially when it comes to changes of the agenda throughout the project, it is again important to have clear responsibilities to avoid stagnation of project progress. Throughout the whole project, communication is a key factor to success and thus has to be managed and controlled to make sure that all necessary information and knowledge is distributed and misunderstandings are prevented. Furthermore, aiming at the financial aspect of collaborations, support programs have to be more visible and accessible for SMEs. Especially for high risk projects, the application for financial funding should be supported. To prevent from cancellation, supervision on financial aspects also has to be defined in the beginning and taken out within the collaboration.

The different hypotheses and factors for successful initiation and implementation with research and SMEs are expected to be representative in the field of product development since they reflect both experience of the authors within numerous projects as well as other studies in this field of research (cf. 
Bigliardi and Galati, 2016). The research will be conducted further on in order to quantify the importance of the mentioned factors. Especially from the SMEs innovation network's point of view, there are several starting points to encourage joint innovation projects and set the right environment for more successful project progresses. A model is introduced in the following section to address the point of identification of fields for collaborative innovation.

\section{A model to identify fields for innovation and collaboration}

Beneficial collaboration for innovation between industry and research requires that potentials and targets of each partner are identified within the initiation phase of a collaborative innovation process. The identification of common interfaces between industrial and research interests can lead to collaborations which meet the specific challenges of an enterprise. At the same time they will allow researchers to offer tailored solutions or to evaluate developed methods in industrial practice. A major challenge is the identification of common fields for innovation and collaboration. On the one hand, many firms are unaware of the possibilities to strengthen their innovation capability. On the other hand, scientific institutions struggle to find practical application for their research and developed methods. In this section we propose a model to support the identification of common targets for collaborative innovation between industry and research, which includes a strategic and operative situation analysis and target definition within the initiation phase of a collaborative innovation process. Therefore, the structure, content and an intended application of the model are described. The introduced model indicates different fields of innovation for SMEs and is structured by four types of knowledge according to (Jong and Ferguson-Hessler, 1996):

1. Strategic knowledge: Least domain specific level of innovation capability from strategic view point in order to analyse and describe a company's innovation capability.

2. Problem-situational knowledge: Problem oriented fields within the strategic levels that indicate relevant fields of action and supports the assessment of a company's capability for innovation.

3. Procedural knowledge: Action focused and domain specific factors to derive specific measures improving the innovation capability and the assessment of the problem-situational fields.

4. Declarative knowledge: Detailed instructions for specific measures within the problemsituational e.g. guide lines or methods descriptions that can be applied practically.

This classification of knowledge, represents the different levels of innovation activities and supports a semiformal top-down process to identify fields to plan innovation activities and collaborations. The content of the different levels within the proposed model was derived from extensive literature review (Neely et al., 2001; Akman and Yilmaz, 2008; Forsman, 2011; Martínez-Román et al., 2011) and interviews in SMEs. In particular, approaches and models for assessing and promoting the innovation capability of enterprises have been considered. In addition guided interviews have been executed, with mainly general managers of SMEs regarding their current state, needs and demands during innovation activities. Figure 2 shows the fields of the strategic level as well as exemplary contents in the sub-levels. The strategic level (1) of the model is divided into an external and internal perspective. It represents six elementary fields of SMEs considering their innovation capability. This strategic level offers companies a first overview and orientation about the current state regarding their weaknesses and strengths for innovations that have emerged from interviews and literature as particularly important. Here, the focus is on the strategic fields of products and services, market and environment, corporate organization, corporate strategy, the fields of network as well as idea and knowledge management. The reason for the importance of networks, idea and knowledge management is the dependency of many SME on external knowledge for innovation due to limited resources and highly specific knowledge within the companies. Within the problem-situational level (2) detailed fields of action are defined that allow a more specific understanding of fields to strengthen the innovation capability. These fields of action and additionally success factors within the procedural level (3) are of high relevance and effect positively the innovation capability of SMEs. Furthermore, it was examined whether the individual fields are suitable for the circumstances of SMEs. Measures designed to meet the needs of large companies, requiring for example a high number of employees and high costs, were not included. As an example, the areas of customer consideration, user consideration, trend and technology orientation, competitor's consideration, 
supplier involvement and market penetration were identified as highly relevant and suitable for the strategic field of market and environment. Within the procedural level (3) success factors were determined in the respective fields of action, such as user identification or user involvement within the field user consideration. Within the declarative level (4), concrete measures were defined, describing strategies, approaches such as design thinking, user-centred design or methods such as persona to positively affect the success factor of user identification.

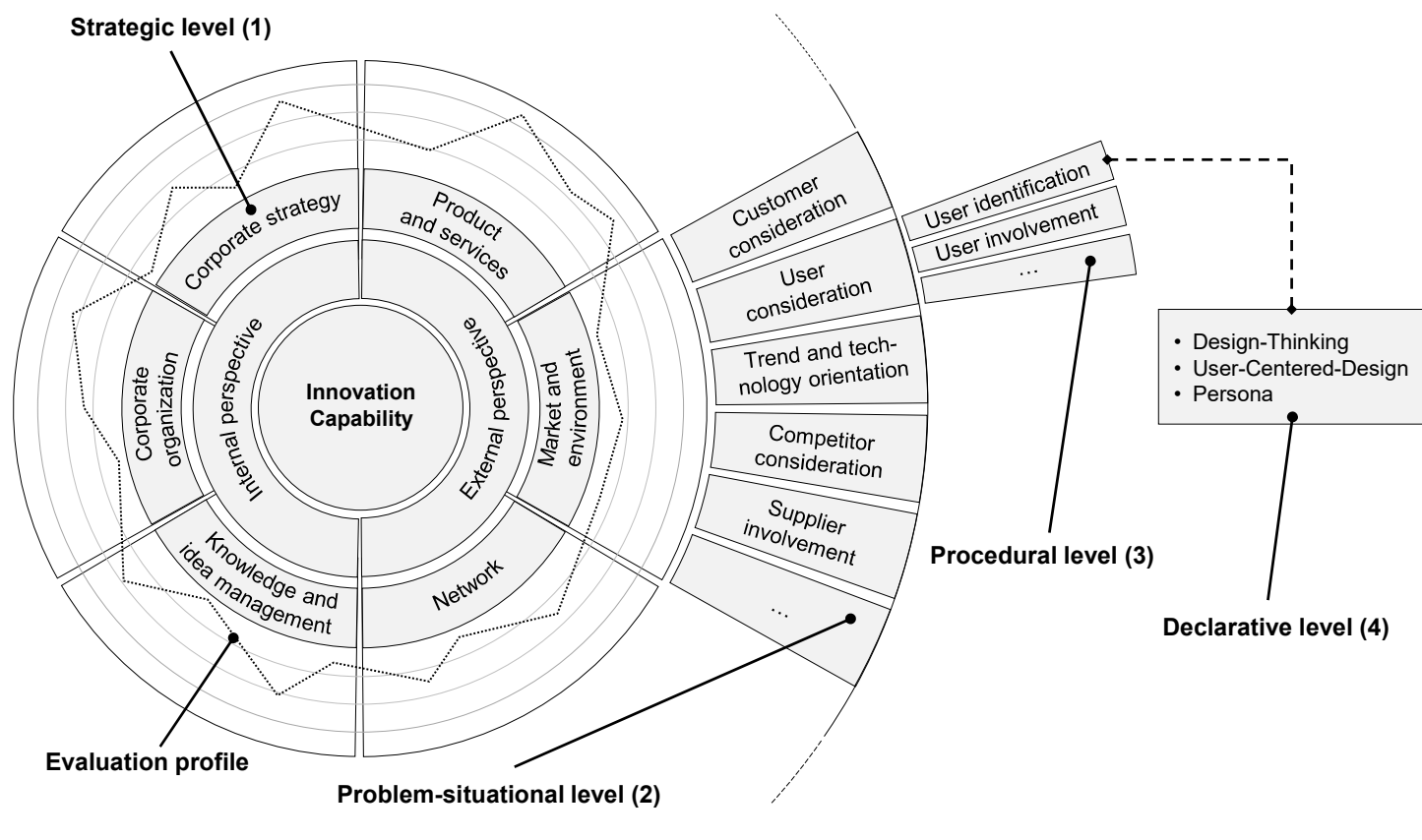

Semiformal methodology

Figure 2. Methodology to identify fields for innovation and collaboration for SMEs

The structure and content of the model provides a semiformal methodology to identify measures to strengthen the innovation capability of SME. The success factors within the procedural level (3) are qualitatively but factually measurable indicators, which can be measured by interviews, questionnaires or moderation involving stakeholders of different organisational levels within a company. The measurement of the success factors forms an evaluation profile of the innovation capability within the strategic (1) and problem-situational (2) levels. This evaluation profile allows a simplified overview of the innovation capability on different concretization levels, allowing to derive specific measures within the declarative level (4) based on the current situation of a company. An effective collaboration can be initiated at this level, which offers specific measures for the industry to strengthen their innovation capability.

\section{Case studies within collaborative innovation processes}

In this section, two case studies considering different scenarios of collaboration between research and industry are described. The first case study on Product Generation Engineering reveals triggers for collaboration in terms of PGE as well as some accompanying challenges. The second case study highlights the need of a comprehensive situation analysis and common target definition during the initiation phase of a collaboration.

\subsection{Case study - collaboration for successful Product Generation Engineering}

The following case study refers to the phases initiation, selection, planning and implementation of the process described in Section 3.1. It shows the role of variations in PGE and the organisational origin of 
reference products as drivers for cooperation as a result of an operative situation analysis. Furthermore examples for success factors regarding the planning and implementation can be derived.

The sample company, an engineering service provider, received the task to develop a blender for lotions in pharmacies. The customer, distributing these machines to pharmacies, approached the company because of rising prices of the former developer and manufacturer of these blenders. The sample company had to develop such a product for the first time. The preceding blender generation, which had been developed by the former producer, was the main reference product for this process. It is hence an example for an external reference product with regard to the understanding of PGE. Along with the task to develop the next product generation, the customer demanded to develop several subsystems newly. Amongst others, a new housing shape was desired which was much more difficult to manufacture, compared to the housing of the previous product generation. This embodiment variation (EV) led to several challenges which caused difficulties throughout the whole development project:

- A specific manner of treatment was necessary for the aluminium of the housing in order to fulfil the requirements of the customer. Only few suppliers in Germany were able to perform this treatment. Hence, the choice of potential collaboration partners in the selection phase was limited. This fact was also known to the partners.

- Looking at the product structure, the housing is a part which has the most connections to other subsystems. Therefore, it was not possible to develop those other subsystems further, as long as the housing was not available.

- As the housing was developed by EV, testing regarding the product functionality was necessary at first. For this purpose, development generation (c.f. Section 2.3) of the housing ('prototypes') had to be produced in a very low quantity in the beginning. These low quantities of ordered products are rather valueless for suppliers, since the production of smaller quantities costs relatively more money per unit compared to the realised profit. Moreover, the developer cannot guarantee that this exact part will be ordered on a mass production scale.

- Initial negotiations about the property of the housing that had to be produced were conducted between developers from the sample company and the distribution staff of the supplier. Due to the less technical focus of the supplier's technical staff, there was a miscommunication about technical feasibilities.

As a result of these challenges, major delays in the supply of the aluminium housing occurred due to the supplier. In addition to that, the delivered units did not meet the sample company's' requirements in terms of dimension and tolerances. An improved collaboration in the form of professional project management, steady communication as well as openness and sincerity (referring to Section 3.2) between the sample company and its supplier would have benefited both parties, since the sample company could have had decreased times for the supply of the product and the supplier would have had less effort on reworking the products.

A driver for collaboration in this case was the access to very specific technological knowledge, reflected by the lack of potential internal reference products in the sample company. In a more general way, the need to use subsystems from external reference products can be a driver for collaboration in the development of a new product generation. The access to specific and sometimes possibly rather new knowledge might not only be a basis for collaboration with specialized companies, but also with research facilities such as universities. Identifying the need for cooperation for successful PGE is part of the strategic and operative situation analysis in the initiation phase. Furthermore was the building of development generations, necessary due to the great new development share, difficult for the supplier from an economical point of view. Hence, this aspect could as well be a starting point for collaborations with not only companies but also research institutes and should be considered especially in the selection or planning phase.

\subsection{Case study - identifying fields for innovation and collaboration}

The second case-study focuses on the application of the model to identify fields of innovation introduced in Section 4. The intention is to highlight its application to initiate a successful collaboration between SMEs and scientific institutions. It is thus linked to the initiation phase of a collaborative innovation 
process, wherein the strategic and operational situation analysis and target definition are of great importance, cf. paragraph 3.1. The sample company develops building-based fire protection solutions. Due to the fact that the sample company is constantly seeking for innovative products a variety of collaborations with scientific institutions have been established in the past in order to strengthen the company's innovation capability. To clarify, the common objectives of a new collaboration between the sample company and a scientific institute, an initial workshop was carried out applying the model proposed in Section 4. Leading positions from different departments and the managing director of the company participated in the workshop. In order to reflect the current state of the company's innovation capability, the participants were asked to evaluate the different fields of action within the model with regard to their individual observations. Therefore, success factors influencing the actions fields were presented to support the understanding of the different fields in the context of innovation capability. During the validation process the results of each strategic field were discussed and current needs and challenges were identified. The results shown in Figure 3 were summarized as the current state of the company. Subsequently the long-term desired stated was asked for each field of action. The resulting gaps between the current and long-term desired state were identified as possible fields for collaboration.

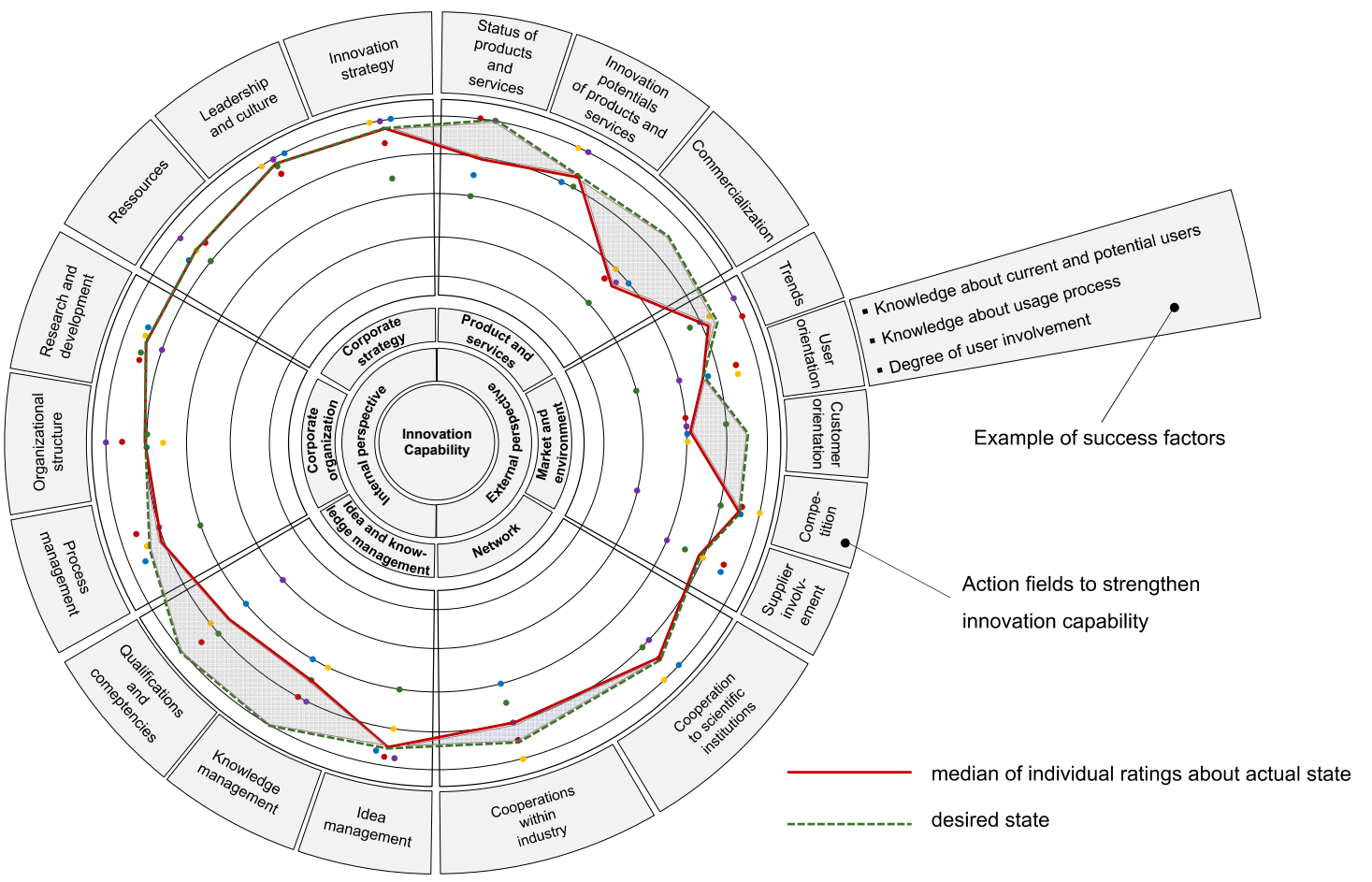

Figure 3. Results of case study - innovation capability

From this structured analysis new insights regarding the innovation capability of the company were derived. As a result of the specific application the areas of marketing, customer involvement, knowledge management as well as qualifications and competencies were identified as relevant fields, which should be considered more concretely to define a collaboration strategy. During the rating process the participants from the company discussed the current challenges and demands in the respective action fields. Statements from different departments within the company offered the participants new perspectives on the company's internal challenges and needs in the area of innovation. Furthermore, the discussions allowed the possible collaboration partners to gain deeper insights about the company. In addition, the potential partners were able to show their competencies in the individual action fields, which lead to the identification of possible interfaces. The case study highlights the benefits of a comprehensive situation analysis and common goal setting before a collaboration is initiated. 


\section{Discussion and conclusion}

As a significant driver for innovation, collaboration in various formats is a promising approach. Major aim of these collaboration is to gather needed knowledge to develop new products or processes, acquire additional resources or get access to new technologies. In practice however, there are different obstacles to overcome when initiating collaborations concerning both, organizational and content related aspects. Therefore, it becomes essential to identify the right field for innovation and the knowledge needed as well as to identify suitable partners for collaboration. Within this contribution, we introduced a model to support fields and measures to foster innovations on strategic as well as declarative level of knowledge. Furthermore, the concept of Product Generation Engineering was introduced as an approach to understand past and plan future innovation focussing on products. Both concepts help to identify the expertise needed to foster innovation.

Aim of this contribution was to discuss findings of successful and ineffective collaborations and give insights to improve collaboration both considering contend and organizational aspects. The hypotheses formulated in Section 3.2 are based on explorative interviews and literature review, however, at this juncture they cannot be seen as universal. Also their relevance has to be investigated by further interviews in order to make quantitative conclusions. It is further important to mention that the hypotheses have been based on a survey that included enterprises from one branch and one region, namely Lower Saxony, Germany. The introduced model to identify fields for innovation and collaboration is based on an extensive literature review and established approaches to structure knowledge. However, it has been applied once in the foreseen way. For this reason its general applicability and validity have to be proven within further studies. Therefore, pilot workshops with SME will be conducted and evaluated by a structured survey. The case studies introduced in Section 5 do not aim at evaluating the collaborations efficiency. They rather constitute two possible constellations of collaboration with partners form research and industry. Further works aim at applying the introduced model (Section 4) to practice and use the formulated hypotheses to build up an innovation network.

\section{Acknowledgements}

Sections of the research presented in this contribution are part of the project Synfonie funded by the German Federal Ministry of Education and Research (BMBF) within the program "Right of way for small firm sector, innovation networks" (01MI707) and managed by the Project Management Agency German Aerospace Center (DLR) and the project InnoLink funded by the Ministry for Science and Culture of Lower Saxony within the program "Europe for Lower Saxony" (ZW6-85003676). The authors are responsible for the contents of this publication. We thank the contributors of the interviews (Synfonie and InnoLink) and the workshop (InnoLink).

\section{References}

Akman, G. and Yilmaz, C. (2008), "Innovative capability, innovation strategy and market orientation: An empirical analysis in Turkish software industry", International journal of innovation management, Vol. 12 No. 1, pp. 69-111. https://doi.org/10.1142/S1363919608001923

Albers, A., Bursac, N. and Rapp, S. (2016b), "PGE - Product generation engineering: Case study of the dual mass flywheel", Proceeding of the DESIGN 2016 / 14th International Design Conference Dubrovnik, Croatia, May 16-19, 2016, The Design Society, Glasgow, pp. 791-800.

Albers, A., Bursac, N. and Wintergerst, E. (2015), "Product Generation Development - Importance and Challenges from a Design Research Perspective", Proceedings of the International Conference on Mechanical Engineering (ME 2015) and the International Conference on Technical Mechanics and Applied Mechanics (TMAM 2015), Vienna, Austria, March 15-17, 2015, INASE, pp. 16-21.

Albers, A., Gladysz, B., Heitger, N. and Wilmsen, M. (2016a), "Categories of Product Innovations - A Prospective Categorization Framework for Innovation Projects in Early Development Phases Based on Empirical Data", Procedia CIRP, Vol. 50, pp. 135-140. https://doi.org/10.1016/j.procir.2016.04.197

Baregheh, A., Rowley, J. and Sambrook, S. (2009), "Towards a multidisciplinary definition of innovation", Management Decision, Vol. 47 No. 8, pp. 1323-1339. https://doi.org/10.1108/00251740910984578

Bigliardi, B. and Galati, F. (2016), "Which factors hinder the adoption of open innovation in SMEs?", Technology Analysis \& Strategic Management, Vol. $28 \quad$ No. $8, \quad$ pp. $869-885$. https://doi.org/10.1080/09537325.2016.1180353 
Blessing, L. and Seering, W. (2016), "Preparing for the Transfer of Research Results to Practice: Best Practice Heuristics", In: Chakrabarti, A. and Lindemann, U. (Eds.), Impact of Design Research on Industrial Practice: Tools, Technology, Training, Springer London, UK, pp. 3-21. https://doi.org/10.1007/978-3-319-19449-3_1

Eversheim, W. (2003), Innovationsmanagement für technische Produkte: Mit Fallbeispielen, Springer Verlag, Berlin. https://doi.org/10.1007/978-3-642-55768-2

Forsman, H. (2011), "Innovation capacity and innovation development in small enterprises: A comparison between the manufacturing and service sectors", Research policy, Vol. 40 No. 5, pp. 739-750. https://doi.org/10.1016/j.respol.2011.02.003

Gerpott, T. (2013), Strategisches Technologie- und Innovationsmanagement, Schäffer-Poeschel Verlag, Stuttgart.

Gürtler, M.R. (2016), Situational Open Innovation: Enabling Boundary-spanning Collaboration in Small and Medium-sized Enterprises, PhD thesis, Technische Universität München.

Hauschildt, J. and Salomo, S. (2011), Innovationsmanagement, Vahlen, München.

Henderson, R.M. and Clark, K.B. (1990), “Architectural Innovation: The Reconfiguration of Existing Product Technologies and the Failure of Established Firms", Administrative Science Quarterly, Vol. 35 No. 1, pp. 930. https://doi.org/10.2307/2393549

Hidalgo, A. and Albors, J. (2008), "Innovation management techniques and tools: A review from theory and practice", R\&D Management, Vol. 38 No. 2, pp. 113-127. https://doi.org/10.1111/j.1467-9310.2008.00503.x

Jong, T. and Ferguson-Hessler, M.G. (1996), “Types and qualities of knowledge”, Educational Psychologist, Vol. 31 No. 2, pp. 105-113. https://doi.org/10.1207/s15326985ep3102_2

Lindemann, U. (2009), Methodische Entwicklung technischer Produkte: Methoden flexibel und situationsgerecht anwenden, Springer-Verlag, Berlin. https://doi.org/10.1007/978-3-642-01423-9

Link, P. (2001), Risikomanagement in Innovationskooperationen: ein Ansatz zur fairen Aufteilung von Chancen und Risiken, PhD thesis, ETH Zürich.

Martínez-Román, J.A., Gamero, J. and Tamayo, J.A. (2011), “Analysis of innovation in SMEs using an innovative capability-based non-linear model: A study in the province of Seville", Technovation, Vol. 31 No. 9, pp. 459475. https://doi.org/10.1016/j.technovation.2011.05.005

Müller, C. (2003), Projektmanagement in FuE-Kooperationen, PhD thesis, TU Hamburg-Harburg.

Neely, A., Filippini, R., Forza, C., Vinelli, A. and Hii, J. (2001), "A framework for analysing business performance, firm innovation and related contextual factors: Perceptions of managers and policy makers in two European regions", Integrated Manufacturing Systems, Vol. 12 No. 2, pp. 114-124. https://doi.org/10.1108/09576060110384307

Osterwalder, A., Pigneur, Y., Bernarda, G. and Smith, A. (2014), Value proposition design: How to create products and services customers want, Wiley, Hoboken.

Peglow, N., Powelske, J., Birk, C., Albers, A. and Bursac, N. (2017), "Systematik zur Differenzierung von Varianten im Kontext der Produktgenerationsentwicklung”, 15. gemeinsames Kolloquium Konstruktionstechnik (KT 2017), Duisburg, Germany, October 5-6, 2017, Universität Duisburg-Essen, Essen, pp. 9-19.

Riitahuhta, A. and Oja, H. (2016), "Successful Industrial and Academia Cooperation in Technology Industry", In: Chakrabarti, A. and Lindemann, U. (Eds.), Impact of Design Research on Industrial Practice: Tools, Technology, and Training, Springer-Verlag, London, UK, pp. 269-280. https://doi.org/10.1007/978-3-31919449-3_18

Ropohl, G. (2009), Allgemeine Technologie: Eine Systemtheorie der Technik, KIT Scientific Publishing, Karlsruhe. https://doi.org/10.26530/OAPEN_422388

Schumpeter, J.A. (1939), Business cycles: A theoretical, historical and statistical analysis of the capitalist process, McGraw-Hill, New York.

Wallace, K. (2011), “Transferring Design Methods into Practice”, In: Birkhofer, H. (Ed.), The future of design methodology, Springer Verlag, Berlin, pp. 239-248. https://doi.org/10.1007/978-0-85729-615-3_21

West, J., Vanhaverbeke, W. and Chesbrough, H. (2006), “Open Innovation: A Research Agenda”, In: Chesbrough, H., Vanhaverbeke, W. and West, J. (Eds.), Open Innovation: Researching a new paradigm, Oxford University Press, UK, pp. 285-307.

Tarık Şahin, Master of Science

Technische Universität Braunschweig, Institute for Engineering Design

Langer Kamp 8, 38106 Braunschweig, Germany

Email: tarik.sahin@tu-braunschweig.de 